Article

\title{
Improving the Distillate Prediction of a Membrane Distillation Unit in a Trigeneration Scheme by Using Artificial Neural Networks
}

\author{
Luis Acevedo ${ }^{1, *}$, Javier Uche ${ }^{2, *}$ and Alejandro Del-Amo ${ }^{3}$ \\ 1 Research Centre for Energy Resources and Consumption (CIRCE), 50018 Zaragoza, Spain \\ 2 Mechanical Engineering Department, Zaragoza University (UNIZAR), 50018 Zaragoza, Spain \\ 3 ABORA SOLAR Company, La Muela, 50196 Zaragoza, Spain; adelamo@abora-solar.com \\ * Correspondence: lacevedo@fcirce.es (L.A.); javiuche@unizar.es (J.U.); Tel.: +34-876-555-512 (L.A.)
}

Received: 24 January 2018; Accepted: 8 March 2018; Published: 13 March 2018

\begin{abstract}
An Artificial Neural Network (ANN) has been developed to predict the distillate produced in a permeate gap membrane distillation (PGMD) module with process operating conditions (temperatures at the condenser and evaporator inlets, and feed seawater flow). Real data obtained from experimental tests were used for the ANN training and further validation and testing. This PGMD module constitutes part of an isolated trigeneration pilot unit fully supplied by solar and wind energy, which also provides power and sanitary hot water (SHW) for a typical single family home. PGMD production was previously estimated with published data from the MD module manufacturer by means of a new type in the framework of Trnsys ${ }^{\circledR}$ simulation within the design of the complete trigeneration scheme. The performance of the ANN model was studied and improved through a parametric study varying the number of neurons in the hidden layer, the number of experimental datasets and by using different activation functions. The ANN obtained can be easily exported to be used in simulation, control or process analysis and optimization. Here, the ANN was finally used to implement a new type to estimate the PGMD production of the unit by using the inlet parameters obtained by the complete simulation model of the trigeneration unit based on Renewable Energy Sources (RES).
\end{abstract}

Keywords: artificial neural networks; machine learning; trigeneration; desalination; membrane distillation

\section{Introduction}

Fresh water and energy are closely related issues. Both are critical and mutually dependent resources, especially in dry and/or isolated areas. Freshwater scarcity is a major challenge facing modern societies [1], as well as the sustainable management of the water cycle by using RES [2] Desalination of seawater and brackish water is maybe the unique solution to alleviate freshwater scarcity nowadays [3]. However, it is an energy intensive process, since distillation processes such as Multi-Stage Flash (MSF), Multi-Effect Distillation (MED) and Membrane Distillation could consume about 50-70, 40-60 and 120-1700 kWh of thermal energy per cubic meter of distillate respectively, whereas membrane techniques such as Reverse Osmosis (RO) consume about 3 to $6 \mathrm{kWh}$ of electricity per cubic meter of permeate [4]. This close relationship has been dealt with, even in oil rich countries, in which RES are also planned to cover the $100 \%$ of the energy demand, including desalination [5]. Despite its energy consumption, membrane distillation (MD) can help to reduce the water-energy stress that societies are facing, especially at a reduced scale and when waste heat from other thermal processes or solar energy is freely available.

Membrane distillation (MD) is a low-heat grade energy consumer and non-isothermal method for water treatment and desalination. Feed water does not need any kind of chemical pre-treatments 
to operate continuously or intermittently at atmospheric pressure. The process can be carried out with temperatures in the range from $70{ }^{\circ} \mathrm{C}$ to $90^{\circ} \mathrm{C}[6,7]$, but lower values could operate with lower production. Desalination was one of the first MD applications [8], since salts are not allowed to be transported through the pores of hydrophobic membranes. This membrane prevents the liquid phase from entering the membrane, whereas its microporous structure and a temperature difference across the membrane allow the transport of water vapor $[9,10]$. Water vapor is produced by an external heat source and is then transported through the membrane and finally condensed by the aid of a coolant; consequently, the distillation process is completed [11]. Different MD configurations can be found according to the coolant agent and system applied. In this paper, a permeated gap type (PGMD) was analyzed, in which a liquid gap is immersed between the membrane and the condensate surface in order to reduce thermal losses. The PGMD is also a spiral wound module type, in the sense that its thermal behavior is rather similar to a counterflow heat exchanger [12].

Mathematical models of membrane distillation processes are based on the superposition of molecular diffusion, Knudsen flow and Poiseuille flow, as well as on semi-empirical equations and correlating process using experimental data to determine the mass transfer coefficients [13]. All MD configurations describe the mechanism of mass transport through the membrane to estimate the working temperatures, production rate and solute retention; thus, all of them can be modelled by the simultaneous heat and mass transfer phenomena [14].

Nevertheless, those models, parameters and correlations are only a subset of a very extensive range of other modeling attempts by other researchers. Moreover, the implementation of these correlations sometimes could be complex, which can be a limitation for practical use in experimental tests and their validation in simulation tools. In other words, mathematical models are rather limited in their practical use for experimental and simulation applications [15].

Despite the existence of mathematical models that can explain the experimental data observed, sometimes the details underlying that data generation are not known. The complete identification of the process is not maybe obtained, but a very good and useful approximation could be found by machine learning. Machines can learn, perform pattern recognition or discover patterns in data. With the help of those found patterns, the process could be understood and some predictions could be made [16]. Thus, many authors have applied the use of artificial neural networks (ANN) for overcoming this situation.

Artificial Neural Networks (ANN) are part of the great variety of machine learning models that exist. In the engineering field, the use of ANN has been motivated due to their ability to discover patters in data through a complex adaptive system. ANN have been successfully developed to solve problems in a variety of applied fields such as plant ecosystems, identification and prediction of disease spread, chemical reactions, temperature regulation, etc. [17,18].

In the case of energy systems, a review of the usefulness of ANN in modelling, prediction and the performance of energy engineering systems is presented by Kalogirou in [19]. Data representing the past history and the performance of a real system are required to provide new estimations of that performance. Regarding water, ANNs have been applied to predict rainfall [20-22], inlet flows to reservoirs, stream flows or peak flows to avoid flooding [23-25], water levels in lakes or aquifers [26,27] or even to detect losses in water networks [28]. In the specific field of desalination, ANNs have been developed for both modelling and simulation. For instance, Gao et al. [29] analyzed the influence of air, cooling water and feed water temperatures in the production of fresh water through a heat pump desalination system. Nevertheless, reverse osmosis (RO) has been the most spread technology investigated. Aish et al. [30] developed an ANN model to weekly predict the total dissolved solids (TDS) and permeate flow rate of RO plants in the Gaza strip. In [31] and in [32], an ANN for a RO plant coupled to a wind turbine was developed to predict the feed flow and operating pressure set points as a function of power, temperature and feed water conductivity. That ANN model took data from unsteady conditions coming from an experimental facility in Gran Canaria Island (Spain) with RO powered by a wind turbine. Barello at al. [33] focused their ANN model to predict the 
permeability constant of the $\mathrm{RO}$ process that could be used for different membranes across a wide range of pressures. Khayet et al. [34] used both, a response surface methodology (RSM) and ANN, to predict the performance index of an RO system as well as to achieve optimal experimental conditions. The inlet ANN parameter corresponds to feed properties (concentration, temperature, feed flow and pressure) under controlled conditions.

Regarding the use of ANN models in MD, their application to a vacuum membrane distillation (VMD) was first presented in [15]. The model was based on experimental input data such as feed temperature, flow rate and concentration as well as the vacuum pressure to predict the distillate flux. Khayet and Cojocaru [35,36] presented two different ANN models to simulate the production of two MD configurations. In [35], they studied an air gap membrane distillation process (AGMD) to describe the distillate flow depending on the air gap thickness, condensation temperature, and the inlet temperature and flow rate of the feed. In [36], a sweeping gas membrane distillation process (SGMD) to predict the distillate flux and the salt rejection was studied in depth. Here, the three considered input parameters were inlet temperature and the velocities of water and air.

The combination of ANN with existing simulation software has been also extensively used, specifically in the field of energy efficiency in buildings and solar energy. The idea is to improve the predictions given by the software with the help of an ANN made from experimental results or running of the software. In this context, Trnsys ${ }^{\circledR}$ is software that has been widely linked with ANNs. For instance, Magnier and Haghighat [37] developed an ANN model based on a validated simulation for the optimization of thermal comfort and energy consumption in a residential house. They found that integrating ANN into optimization could considerably reduce the simulation time compared with classical optimization methods. In [38], a multi-objective optimization model using genetic algorithms and ANNs to improve energy consumption and to reduce thermal discomfort and costs in a school building was presented. Training data sets were also obtained from parametric runs. Buratti et al. [39] compared the different approaches of ANN and the simulator of the energy performance of buildings in Perugia, Italy. They found that the ANN model results were closer to the measured data than the results from simulation. Furthermore, Souliotis et al. [40] combined the use of an ANN model trained with experimental uncontrolled data from a solar collector with the simulator to improve the results of that integrated collector storage. To sum up, an extent review of the ANN and simulation is available in [41].

As far as the authors' know, this study is the first implementation of an ANN to a PGMD module. In this paper, the ANN is devoted to improve the prediction results of the permeate flux of this module, which is fully integrated in a trigeneration unit based on the hybrid production of desalted water by consuming heat (PGMD) or power (RO) coming from RES. In this manner, a more accurate prediction of the three plant products (desalted seawater, SHW and power) could then be done. A first attempt to include the PGMD in the integrated scheme was based on a simple regression model that accounted for a reduced band of incoming operating parameters. Thus, higher distillate rates were estimated and therefore fewer energy resources were derived to supply the PGMD, with the alternate productions of SHW and power also affected.

On the other hand, the ANN has been constructed using several experimental data sets under different conditions and does not depend on the energy source applied, as will be explained in Section 3.1.2. Those data have been precisely the key to provide a better performance of the ANN model. Most of the datasets belong to a quasi-static process condition, which is typical in a module immersed in a rather complex unit fully supplied by two aleatory RES sources (solar and wind energy): in the case of the PGMD module, the heat supply is smoothed out by the existence of the hot water tank [40]. To sum up, the ANN contributes to the validation of the integrated simulation model, which is being tested with the final aim of scaling up those trigeneration schemes fully supplied by RES for small remote settlements. Nevertheless, this ANN model can be freely exported to any kind of simulation tool or to a control system, in order to predict the performance of any other PGMD module with similar characteristics. 


\section{System Description}

\subsection{Trigeneration Unit Based on RES}

The PGMD module comprises part of one of the main subsystems of a hybrid pilot trigeneration unit which is fueled by solar and wind energy and produces power, desalted water by means of the PGMD and an RO module, and Sanitary Hot Water (SHW). The pilot unit was designed to cover the typical water and energy demands of a single family home isolated from the grid. There are 4 main subsystems in the plant, as shown in Figure 1. The solar loop is composed of four photovoltaic thermal (PVT) collectors and one evacuated tube collector (ETC). The power loop consists of the supply of photovoltaic arrays aided with a micro-wind turbine and the storage on batteries to manage power demand. Solar energy is collected in a storage tank which feeds both the SHW demand and the PGMD unit (SHW loop). Finally, the fresh water loop includes the PGMD and the RO units, with the RO as an additional power demand. Details of the design simulation can be found in [7], where a complete sensitivity analysis was presented. The project was simulated with weather data from Zaragoza city, located in the northeast of Spain. The simulation was carried out for a complete year having a time step of $12 \mathrm{~min}$ (43,800 iterations).

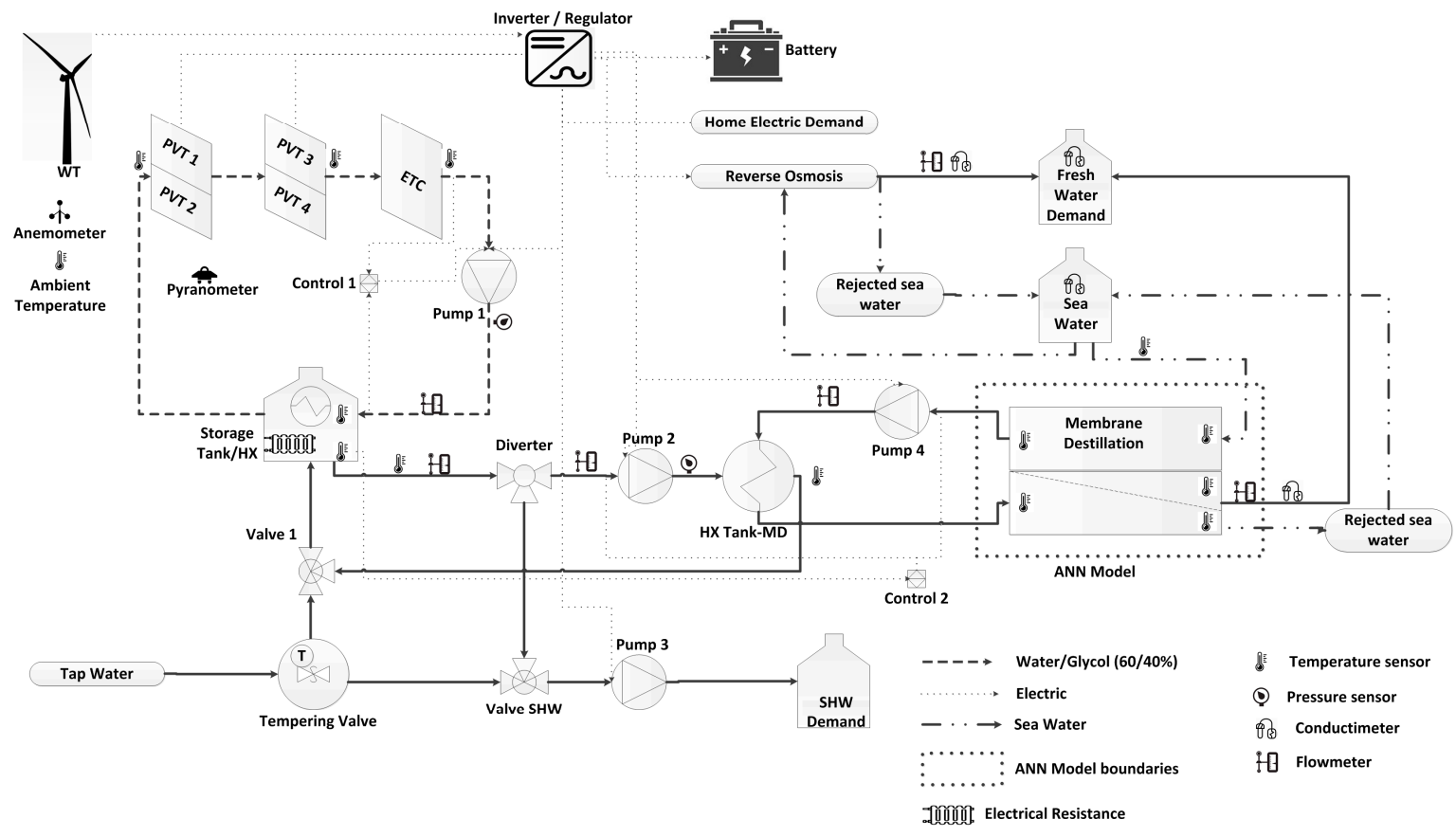

Figure 1. Trigeneration Scheme.

The complete system simulation was later expanded by studying the effects of the battery capacity and electric load [42]. Exergy analysis has also been implemented to reduce local irreversibilities [43,44].

The trigeneration pilot plant was fully erected during the year 2016 in Zaragoza, Spain [45]. In the experimental facility, thermal energy is stored in a $325 \mathrm{~L}$ water tank that feds the PGMD through a heat exchanger (HX Tank-MD in Figure 1). The control system number 1 presented in the same figure allows obtaining stable temperatures inside the tank due to hysteresis between solar collectors and tank temperature. Tank stratification permits hot water delivery at almost constant temperatures to HX Tank-MD to feed the membrane system. The PGMD is a commercial module and contains a spiral wound desalination membrane with a maximum capacity of $20 \mathrm{~L} / \mathrm{h}$ with a very pure distillate ( $<2 \mathrm{ppm}$ of salinity). It has a total exchange area of $10 \mathrm{~m}^{2}$, with the corresponding condenser, distillate and evaporator channels as explained in [13]. Usually, the set-up temperature to feed the PGMD was $70^{\circ} \mathrm{C}$, but lower temperatures could activate the PGMD. The pilot unit included a sophisticated 
control and monitoring system. Five temperatures were measured at the PGMD inlet/outlets. Inlet and return flow rates from the HX Tank-MD were also measured to estimate the PGMD thermal energy consumption. Seawater tank and outside temperatures are measured as well. All temperatures were measured by PT-100 sensors $\left( \pm 0.2^{\circ} \mathrm{C}\right)$ and gathered every minute by an automata, which also controls valves, pumps and any other safety systems. The PGMD production rate and SHW flow rate to the PGMD (via the HX Tank-MD) and SHW demand were visually measured by three flowmeters, with an accuracy estimated in a range of $\pm 2 \%$ after calibration. Finally, conductivity of the seawater tank, PGMD distillate and RO permeate are measured by different conductivity meters, but only the distillate quality is recorded by the automata. Distillate flow will be then be a varying function of the heat supplied to the PGMD module, which provokes a temperature drop between the evaporator and condenser channels of the PGMD. These temperature variations occur gradually, so the system can be considered a quasi-static process and data can be recorded for different temperatures scenarios.

\subsection{PGMD Preliminary Distillate Prediction}

Figure 2 shows a sketch of the PGMD where feed water (flow 3) enters into the condenser, takes energy and then increments its temperature due to the heat transfer from the evaporator and distillate channels (flow 4). Feed water is then reheated by an external heat source by means of the HX Tank-MD (flows 1 and 2). Then, hot feed water enters the evaporator (flow 5) where some vapor is produced and the remaining liquid transfers the heat to the condenser side. Finally, vapor passes through the membrane and then it is condensed to obtain distillate (flow 7). The salinity of the remaining brine is then slightly increased (flow 6).

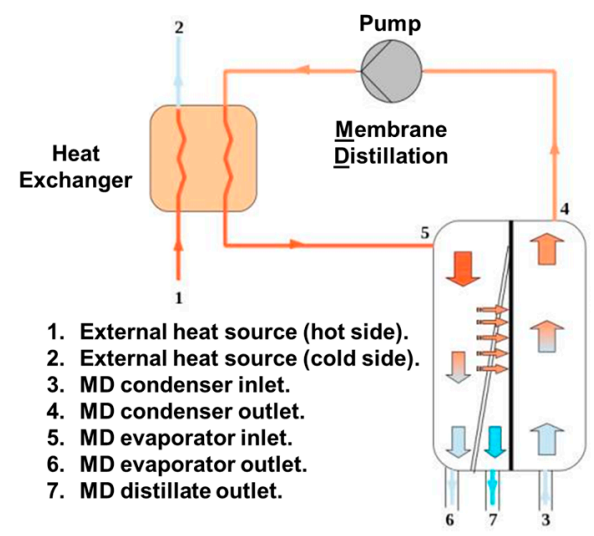

Figure 2. Membrane distillation scheme: PGMD unit.

In [7], the PGMD production was estimated by a linear correlation based on experimental results from Winter et al. [13]. The regression parameters were chosen in such a way that everyone can compute the product of a PGMD independently from the heat source type. As already explained, the distillate depends on the different temperatures and pressures on both sides of the membrane. Since the purpose of this investigation is to create a model that does not depend on external sources, evaporator and condenser inlets (the hottest and coldest zones inside the membrane, respectively) only the thermal inputs, as well as the feed water flow, must be considered. By taking into account those variables, the model can forecast the fresh water production. The mathematical linear regression model obtained was:

$$
m_{\text {dist }}=-5.48+0.043 m_{\text {feed }}+0.079\left(T_{e i}-T_{c i}\right)
$$

This linear model produces acceptable results mainly when it is applied to a spiral wound membrane unit with $10 \mathrm{~m}^{2}$ with temperature drops of about $55^{\circ} \mathrm{C}$ between the inlets of the evaporator $\left(T_{e i}\right)$ and condenser $\left(T_{c i}\right)$, and feed water $\left(m_{f e e d}\right)$ of $35 \mathrm{~g} / \mathrm{kg}$ of salinity with a flow range from $200 \mathrm{~L} / \mathrm{h}$ to $500 \mathrm{~L} / \mathrm{h}$. As stated in [7], this model can give a first estimation even if temperature differences 
are lower than $55^{\circ} \mathrm{C}$; then, it can be used as a first approach during the first design stage of the trigeneration plant.

\subsection{PGMD Experimental Validation}

In order to characterize the PGMD production, the abovementioned three measured parameters have been taken into consideration (inlet condenser and evaporator temperatures as well as seawater feed flow). Two kinds of data sets were obtained from the experimental facility. The first dataset was obtained by using a $3 \mathrm{~kW}$ heating resistance immersed in the hot water tank ("electric"). The hot water temperature in the tank was monitored with three PT-100 sensors, two inside the tank and one at the water outlet to control stratification and the temperature of the heat MD source, respectively. By using the heating resistance, the temperature in the MD heating source was kept constant at different values to perform the tests at a steady state. Those tests were carried out from December 2016 to February 2017 within the performance tests of the PGMD module. Thus, the second dataset ("solar") was obtained from the complete operation of the trigeneration facility by only using solar energy (heating resistance remained off); here, distillate mainly depended on the weather conditions and heat derived to supply the SHW demand. However, as explained before, the stratification inside the tank allows delivering hot water at an almost constant temperature during the characterization of the PGMD with solar energy, thus assuming that in those tests, a quasi-static process is occurring.

Figure 3 shows the behavior of the system during a solar test in July. At the beginning of the day, the tank temperature was about $65^{\circ} \mathrm{C}$ and the heating process due to hysteresis started; the temperature of the tank increased as the sun radiation intensity increased. When the temperature in the hot water outlet zone reached about $75{ }^{\circ} \mathrm{C}$, the MD test started. It can be seen that due to the tank stratification, a constant temperature can be maintained during tests. Due to the high energy rate of the MD evaporator, the tank temperature and therefore that of the evaporator inlet went down; nevertheless, it can be observed that the system operated at almost constant temperature levels. Datasets for different temperatures and mass flow rates feeding the MD unit were gathered in the test bench. A solar dataset was obtained in a campaign from May to October 2017. Table 1 shows the operating range of the variables used during the data collection.

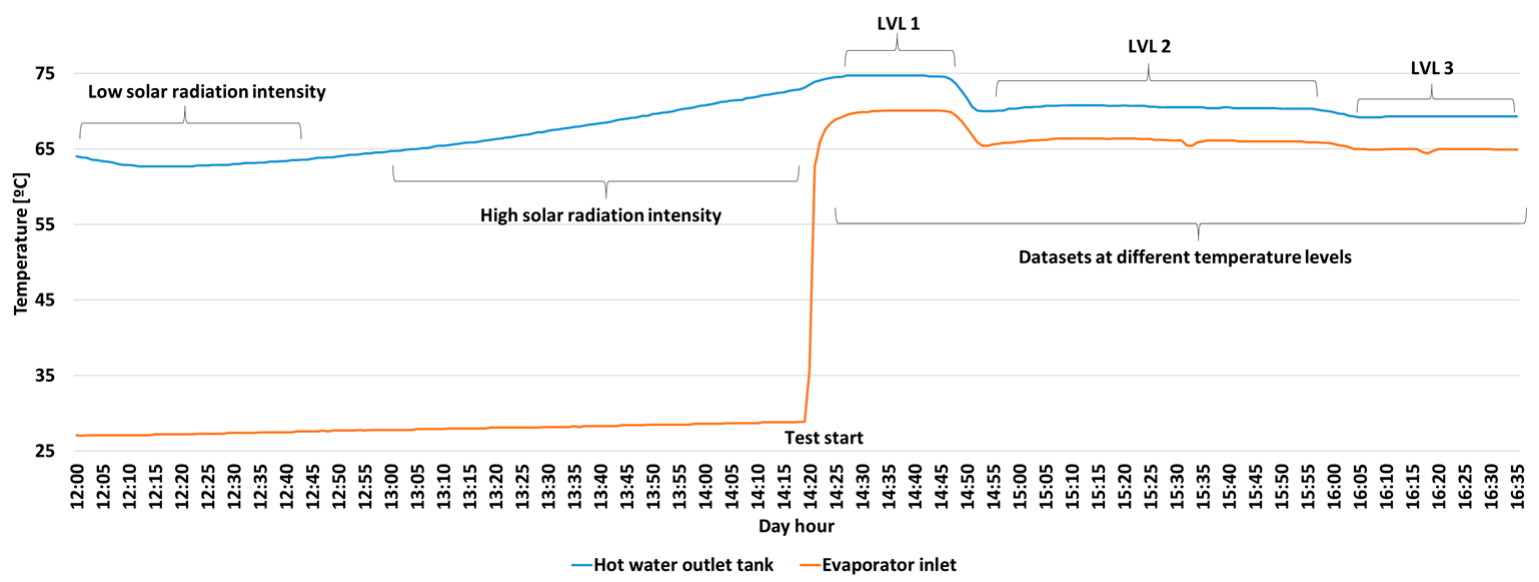

Figure 3. Quasi-static process between heat source and MD. 
Table 1. Operating range of the inlet parameters in experimental datasets.

\begin{tabular}{ccc}
\hline Variable & Electric Tests & Solar Tests \\
\hline Data set samples & 372 & 11,272 \\
Test number & 18 & 53 \\
Average test duration $(\mathrm{min})$ & 118 & 368 \\
Feed water $(\mathrm{L} / \mathrm{h})$ & $150-500$ & $300-500$ \\
Evaporator inlet temperature $\left({ }^{\circ} \mathrm{C}\right)$ & $60-75$ & $60-80$ \\
Condenser inlet temperature $\left({ }^{\circ} \mathrm{C}\right)$ & $10-30$ & $18-30$ \\
Maximum distillate production $(\mathrm{L} / \mathrm{h})$ & 21.12 & 19.48 \\
Ambient temperature $\left({ }^{\circ} \mathrm{C}\right)$ & $-5-15$ & $10-43$ \\
Solar incident irradiation $\left(\mathrm{W} / \mathrm{m}^{2}\right)$ & - & $100-1150$ \\
Wind speed $(\mathrm{m} / \mathrm{s})$ & - & $0-17.2$ \\
\hline
\end{tabular}

Once enough data were collected, results from simulations and real measured data could be compared. If experimental production of the PGMD and the one predicted by the simulation in their linear regression model from Equation (1) are balanced, a considerable deviation in the prediction is found. As an example, Figure 4 shows all the temperatures and permeate samples collected in one typical summer solar test (24 July 2017) and the product from the linear regression simulation, both with a seawater feed of $300 \mathrm{~L} / \mathrm{h}$. Figure 4 (below) shows that the temperature at the condenser inlet (blue lines) was very similar in both cases, but the temperature at the evaporator inlet (red lines) was slightly over predicted by the simulation. As that temperature difference is the driving force to produce distillate (green lines), and a deviation of $6{ }^{\circ} \mathrm{C}$ was found, a rather high estimation of the distillate was encountered. Although it is an acceptable value considering that the simulator uses standard weather conditions, constant efficiencies and time step approximations, from Figure 4 (above), we can conclude that the model previously presented in [7] must be strongly improved if PGMD production has to be finely predicted in the complete trigeneration scheme erected.
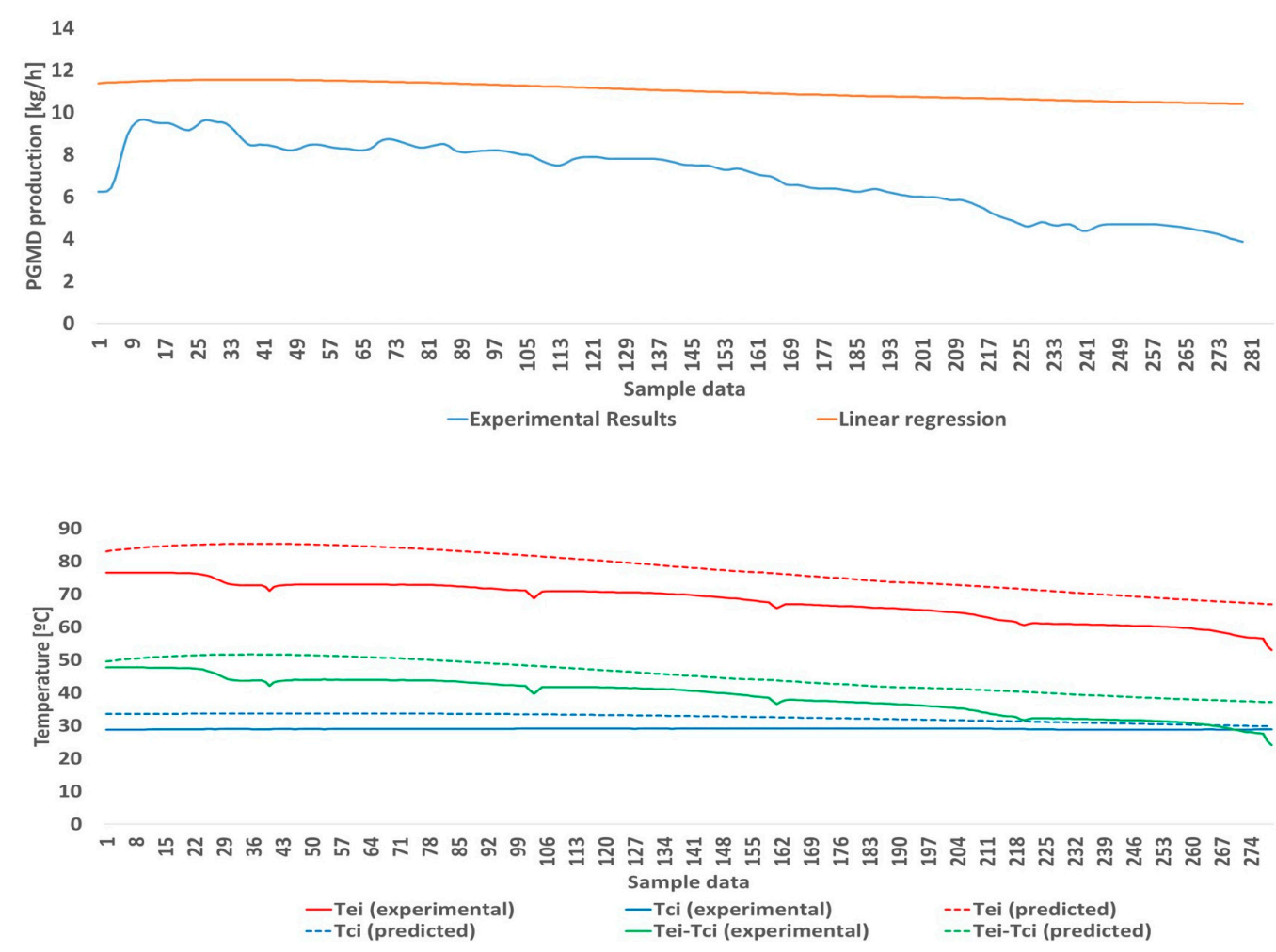

Figure 4. Comparison of experimental and predicted PGMD production (Above) by simulation. The same for the three analyzed inlet parameters (Below). Test on 24 July 2017. 
On the other hand, ANN models do not require detailed information about the system, that is, a standard experimental design is not required to develop the model, and different experimental designs may be used [34]. They can learn the relationship between the input parameters and the test variable results, as non-linear regression might perform [40]. To conclude, ANN models are very flexible and it is not necessary that the variables follow a constant step of variation [35]. They are able to adequately learn the specific behavior of the entire system and to predict the production in the face of variations in any of its operating parameters [32].

Consequently, an ANN scheme has been proposed with data obtained from the electric tests, the solar tests and the combination of both datasets in order to improve the prediction of its distillate under any other operating conditions that could feed the PGMD module immersed in that trigeneration scheme. If temperature conditions are controlled, a recurrent neural network model is not necessary; this fact has already been proven in other types of ANN membrane models presented in $[35,36]$. Here, the ANN model was developed by using Matlab R2017b software (version 9.3.0.713579 (R2017b), MathWorks, Natick, MA, USA) and the standard functions included in the Neural Network Toolbox. In particular, the Levenber-Marquardt back-propagation algorithm was applied [46]. Levenberg-Marquardt is a curve-fitting method that improves the solution to problems by only adjusting the learning rate repeatedly. This algorithm combines two minimization methods such as the gradient decent and Gauss-Newton methods [17].

\section{ANN Model}

The definite structure of the selected ANN is shown in Figure 5. Measured inlet temperatures of the evaporator $\left(T_{e i}\right)$ and condenser $\left(T_{c i}\right)$ and seawater feed flow in the PGMD $\left(m_{\text {feed }}\right)$ were used as the ANN inputs. The output of the ANN is the distillate produced $\left(m_{\text {dist }}\right)$. The developed ANN-based correlation will be then adopted to replace the existing linear regression correlation in the previous simulation presented in [7]. Regardless, the mathematical model of this ANN for this PGMD can be extrapolated to any other software.

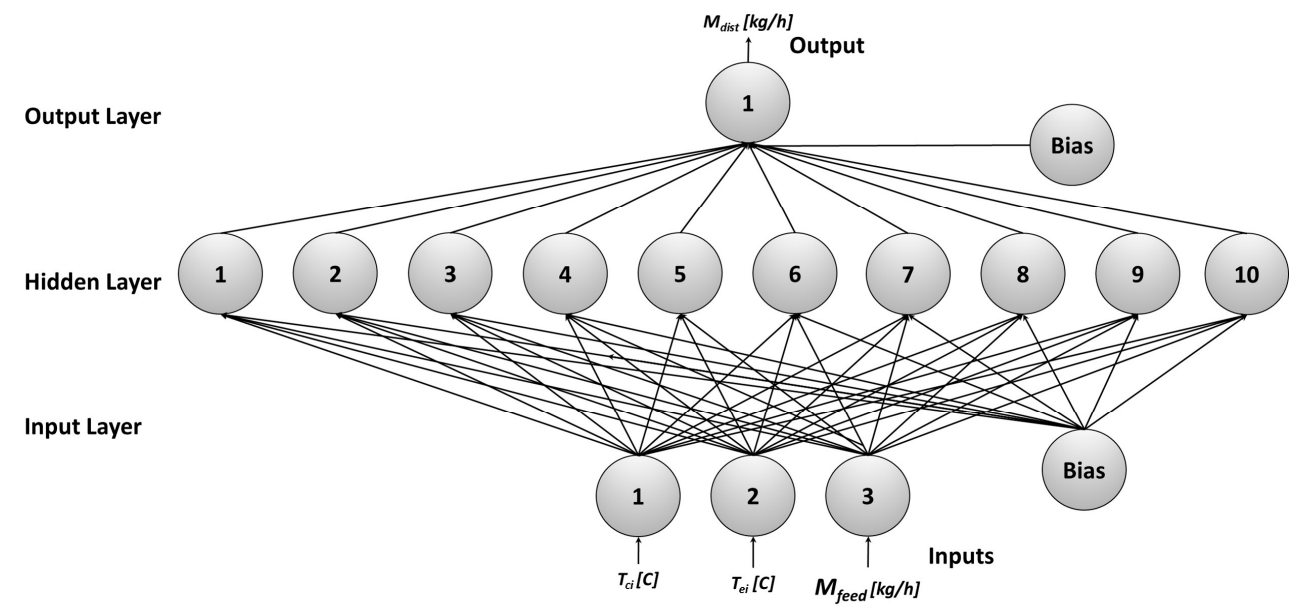

Figure 5. ANN structure.

The ANN modelling was performed using the following procedure:

1. Data preprocessing: Data from the automata were prepared. Some outliers in data were identified and eliminated. Inputs and outputs were carefully reviewed to provide valuable information, avoid noise and to assure the correct prediction of the ANN.

2. Structure selection: The architecture of the ANN model includes three inputs, one hidden layer and one output layer with a single neuron. A small sized ANN was preferred in order to facilitate exportation and therefore to consume fewer computational resources. 
3. Inputs and targets are normalized following this equation:

$$
y=\frac{\left(y_{\max }-y_{\min }\right)\left(x-x_{\min }\right)}{\left(x_{\max }-x_{\min }\right)}+y_{\min }
$$

where $x$ represents finite and real values to normalize, $y$ represents the normalized values, $y_{\min }$ and $y_{\max }$ define the limits of the normalization $(-1$ to 1 in case of Tanh, and 0 to 1 for Log-Sigmoid).

4. Training: The training phase is performed by constantly updating weights and biases to achieve a certain Mean Square Error (MSE, at least 0.5) and Coefficient of Determination R (at least 0.95). In this phase, $90 \%$ of the available samples were taken.

5. Validation and testing: The $10 \%$ remaining available samples were chosen for validation and testing. In both stages of the ANN creation, a minimum value of 0.95 is required for $R$.

6. Development: After the learning phase, the optimal values of the weights and biases are saved, and the ANN is developed

7. Exportation: Once the ANN has proved to provide most accurate values of the PGMD production, the model is exported if it is going to be used in any other applications.

The ANN model can be exported in a matrix form as follows:

$$
m_{\text {dist }}=\left[w_{k j}\right] \text { Activation Function }\left(\left[w_{j i}\left[\begin{array}{c}
T_{c i} \\
T_{e i} \\
m_{\text {feed }}
\end{array}\right]+\left[w_{0 j}\right]\right)+w_{0 k}\right.
$$

Note that normalization and de-normalization may be needed, which implies the inclusion of one or more parameters in the above equation.

\subsection{Parametric Modelization of the ANN Performance}

The analysis of the main parameters describing the ANN performance is presented next. First, the number of neurons in the hidden layer is studied in depth. Second, the dataset gathered to create the ANN was analyzed. Third, the activation function used was also studied.

\subsubsection{Number of Neurons in Hidden Layer}

There is no common rule to apply to find out the optimum number of neurons in the hidden layer. Some authors suggest that at least it would be equal to the $75 \%$ of the numbers of neurons in the input layer [47]. On the other hand, others suggest that the simplest way is to identify that number by trial and error up to the minimum error on the validation dataset [17]. Thus, a parametric study was performed in this issue.

The first approach used was based on a relationship among the number of samples in the dataset, the neurons in the input layer $(N)$ and neurons in hidden layer $(n)$ as presented by Martín et al. in [47].

$$
\frac{\text { Samples }}{2 N}<n<\frac{2(\text { Samples })}{N}
$$

Based on this equation, the number of neurons in hidden layer for the case of the electric dataset was between 68 and 248, and for the case of solar dataset, was between 1878 and 7514 . The trained ANN model took the form 3-68-1; the performance (MSE) was found to be 0.38 with an R value of 0.9599 , which at first seemed to be an adequate model. However, when external data from [13] were tested, the model proved to be over fitted, and the number of neurons had to be decreased. 
From the same reference [47], the classical Kolmogorov approach can also be used to estimate the minimum number of neurons in the hidden layer as:

$$
n=2 N+1
$$

If the effect of the dataset size is neglected, the minimum number of neurons in the hidden layer is 7. Therefore, nine different ANN models were trained using inputs from the electrical and solar datasets, varying the number of neurons from 7 to 15 . Figure 6 shows the parametric results of varying the number of neurons in the hidden layer.

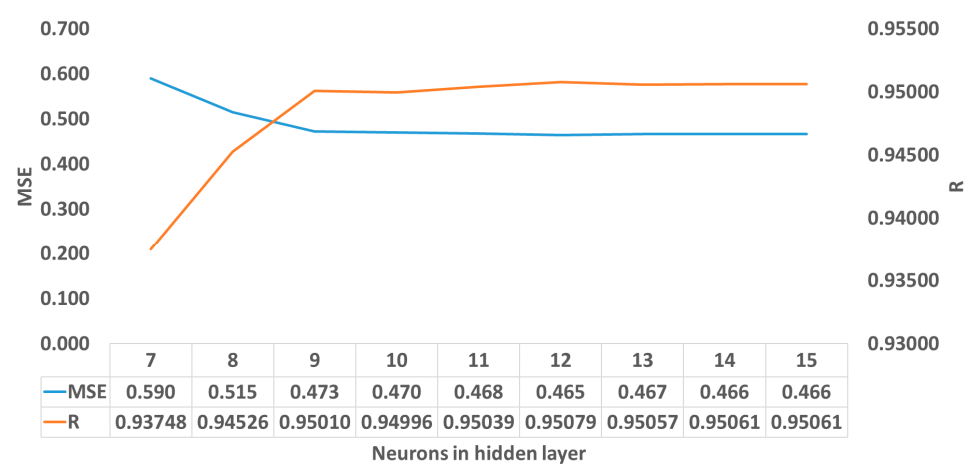

Figure 6. MSE effect of number of neurons in the hidden layer.

In Figure 6, it can be seen that the MSE of the ANN model with 7 neurons is $25 \%$ higher than the case with 10 neurons and $26 \%$ higher than the case with 15 neurons. The MSE is decreased as the number of neurons is increased. However, it can be clearly observed that the difference among the models from 10 to 15 neurons is minimal, about $0.8 \%$. The same trend can be observed with the coefficient of determination, $\mathrm{R}$. The model with 7 neurons is $1.31 \%$ and $1.38 \%$ smaller than the cases with 10 and 15 neurons, respectively. The effect on the $R$ value of the number of neurons in the hidden layer can be observed in Figure 7 for the case of 7, 9, 10 and 15 neurons. Once again, it can be seen that after 10 neurons, the performance of the ANN model remains at $R$ values very close to a value of 0.95 .

The optimum number of neurons in hidden layer was then established between 10 and 15 . Considering that the model with 10 neurons in the hidden layer is easier to export to external systems, later analysis will be based on the 10 neuron case. The number of neurons in the hidden layer reported here coincides with other ANN models presented in $[35,36]$ for similar membrane distillation systems. Nevertheless, the model with 15 neurons is alternatively presented as supplementary information at the end of the paper. 


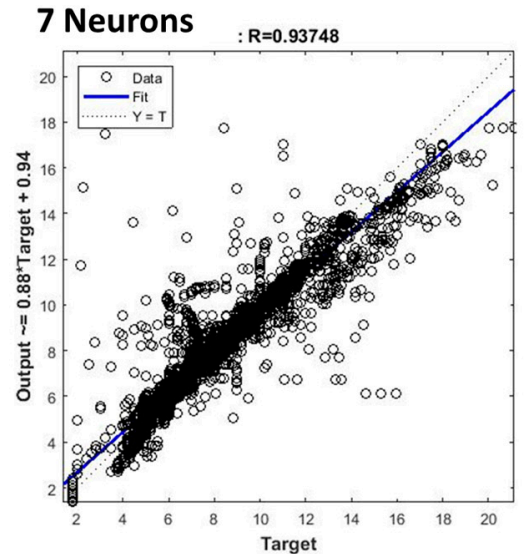

10 Neurons

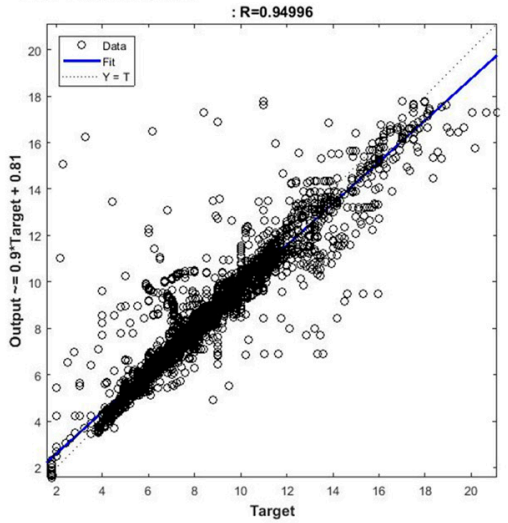

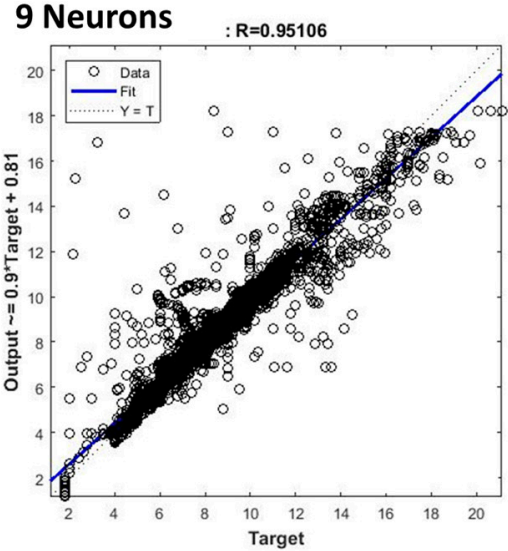

15 Neurons

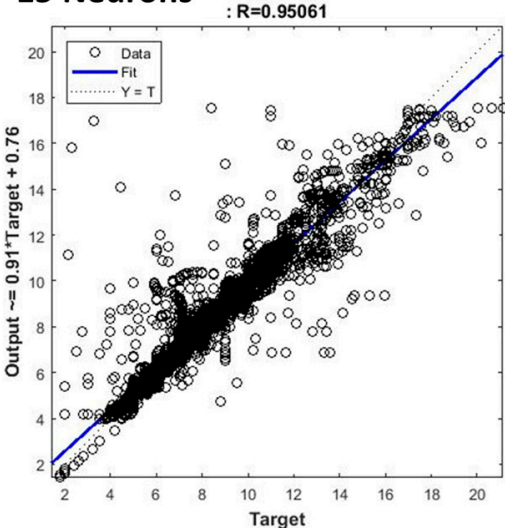

Figure 7. $\mathrm{R}$ value depending on the number of neurons in the hidden layer.

\subsubsection{Dataset Collection}

Since the ANN model is independent of the heat source, it is possible to present, compare and combine experimental data under different conditions by only knowing the three abovementioned parameters. It was found that the performance of the ANN improved as the number of experimental data sets increased; thus, three data sets were consecutively analyzed to train the ANN. The first two datasets correspond to the electric and solar, the third one is the combination of both, electric and solar. The third data set was found to be the best solution in terms of the ANN accuracy. The overall performance of the ANN based on the different experimental data sets (electric, solar and combined) is presented in Table 2.

Table 2. ANN and linear regression model performance.

\begin{tabular}{ccccc}
\hline Parameter & Linear Regression & ANN (Electric) & ANN (Solar) & $\begin{array}{c}\text { ANN (Both } \\
\text { Datasets) }\end{array}$ \\
\hline MSE & 30.61 & 10.45 & 0.86 & 0.47 \\
R & 0.48 & 0.58 & 0.91 & 0.95 \\
\hline
\end{tabular}

In detail, Figure 8 shows the performance of the ANN fed by the three data sets of experimental values and the linear regression previously presented in [7]. 

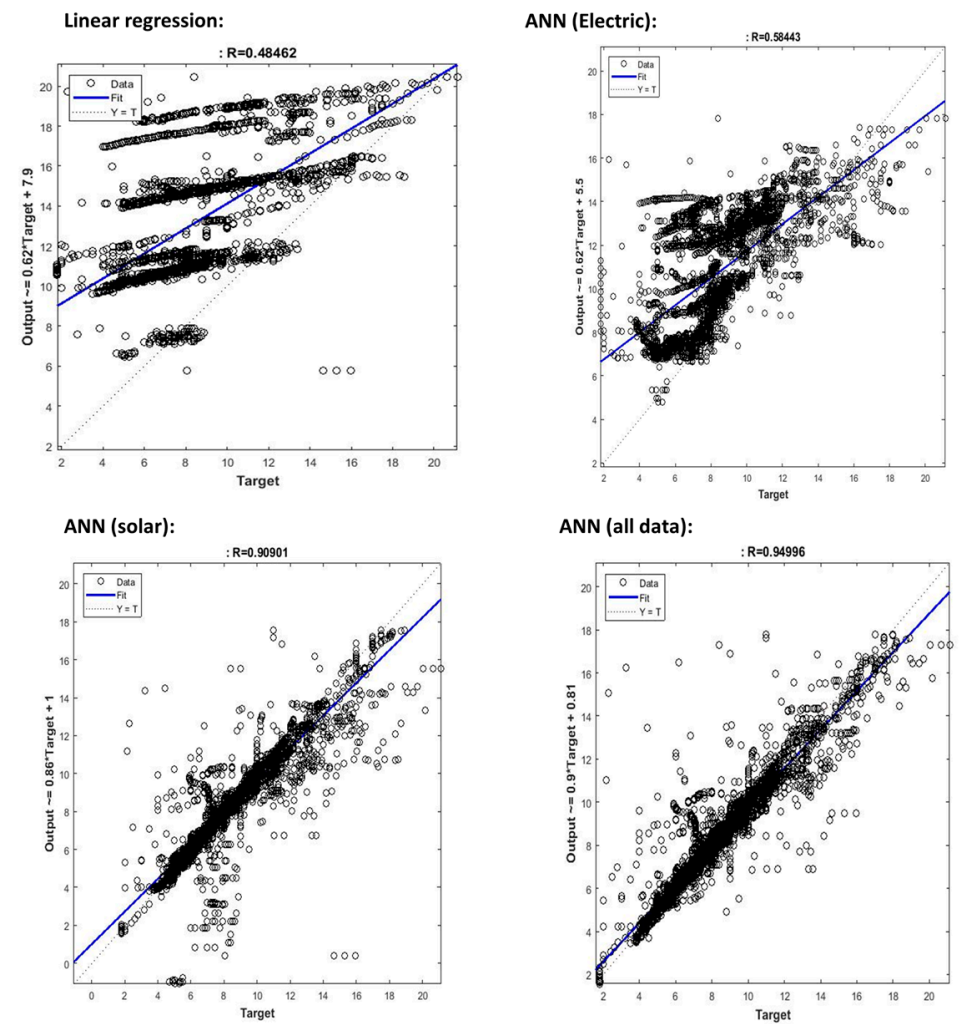

Figure 8. Performance of the linear regression model and the ANN depending on the data sets used.

It can be seen that the linear regression presented in previous investigations is not very accurate; however, it gave us a first approximation to estimate the PGMD production under real conditions (Figure 8, top left-hand corner). Alternatively, the ANN model fed by only electric data tests did not strongly improved the linear regression, since its MSE decreased from 30.61 to 10.45 and the R increased from 0.48 to 0.58 (Figure 8, top right-hand corner). Table 3 shows some typical inlet and outlet parameters of some selected samples from the electric dataset at different temperature levels as described in Section 2.3.

Table 3. Some selected samples from the electric experimental tests (372).

\begin{tabular}{ccccc}
\hline Sample & $T_{e i}\left({ }^{\circ} \mathbf{C}\right)$ & $T_{c i}\left({ }^{\circ} \mathbf{C}\right)$ & $m_{\text {feed }}(\mathrm{L} / \mathrm{h})$ & $m_{\text {dist }}(\mathrm{L} / \mathrm{h})$ \\
\hline 65 & 66 & 12 & 200 & 6.48 \\
101 & 68 & 19 & 300 & 10.80 \\
122 & 61 & 25 & 400 & 12.84 \\
133 & 70 & 22 & 500 & 17.76 \\
154 & 71 & 16 & 200 & 7.68 \\
188 & 69 & 18 & 300 & 11.4 \\
219 & 69 & 20 & 400 & 12.60 \\
328 & 64 & 20 & 500 & 15.72 \\
\hline
\end{tabular}

However, significant progress was found when solar tests used the training information for the ANN: the MSE decreased to 0.86, and R increased to 0.91 (Figure 8, bottom left-hand corner). Table 4 shows some random samples taken from the solar conditions corresponding to the solar set at different temperature levels as described in Section 2.3. 
Table 4. Some selected samples from the solar experimental tests $(11,272)$.

\begin{tabular}{ccccc}
\hline Sample & $\boldsymbol{T}_{\boldsymbol{e i}}\left({ }^{\circ} \mathrm{C}\right)$ & $\boldsymbol{T}_{\boldsymbol{c i}}\left({ }^{\circ} \mathrm{C}\right)$ & $\boldsymbol{m}_{\text {feed }}(\mathrm{L} / \mathrm{h})$ & $\boldsymbol{m}_{\text {dist }}(\mathrm{L} / \mathrm{h})$ \\
\hline 9 & 77.8 & 24.5 & 470 & 17.5 \\
274 & 69.2 & 27.3 & 450 & 12.1 \\
510 & 66.4 & 22.2 & 400 & 10.7 \\
739 & 61.7 & 25.1 & 320 & 6.0 \\
1220 & 66.1 & 21.7 & 300 & 8.0 \\
$\ldots$ & $\ldots$ & $\ldots$ & $\ldots$ & $\ldots$ \\
7879 & 75.2 & 26.8 & 310 & 9.9 \\
8193 & 67.9 & 29.6 & 300 & 6.9 \\
10201 & 56.9 & 27.5 & 350 & 4.8 \\
10580 & 67.0 & 27.1 & 300 & 6.6 \\
11006 & 71.2 & 26.7 & 310 & 8.5 \\
\hline
\end{tabular}

Finally, when all data were combined, the ANN model gave the most accurate results, with the lowest value of MSE (0.47) and highest $\mathrm{R}$ value (0.95) (Figure 8, bottom right-hand corner). Thus, this last set including the combined electric and solar test conditions was used for the definite ANN.

Alternatively, Figure 9 presents the global comparison of the 11,643 experimental samples of distillate produced in the PGMD module (in blue) with those predicted by the linear regression and by the ANN models (with three different data sets, in red).

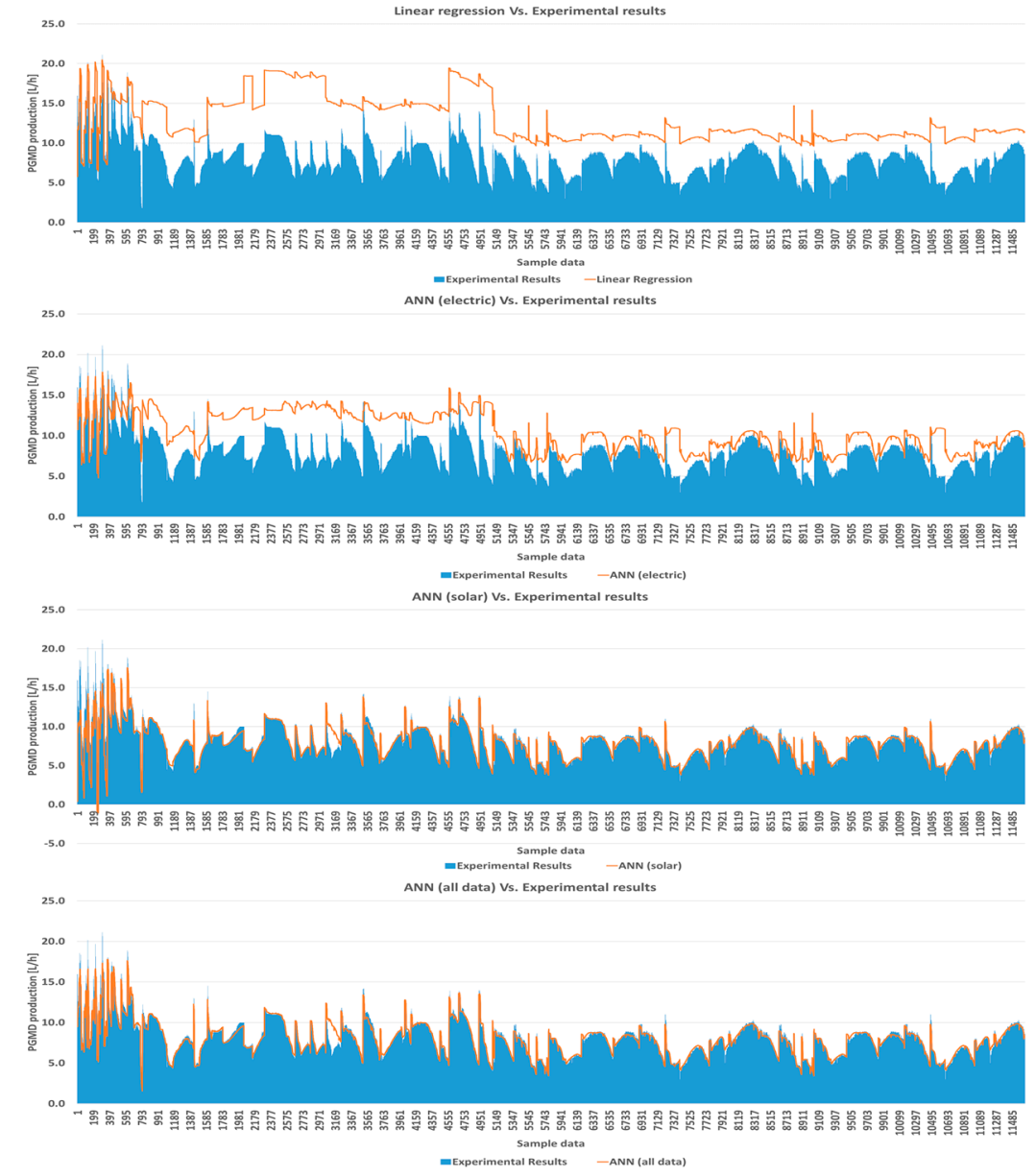

Figure 9. Experimental (blue) and predicted (red) values for the simulation type and ANN trained with diverse data sets. 
As presented previously in Figure 4, the linear regression overestimates the production of the PGMD (first). This overestimation is clearly decreased with the use of the ANN model based on the electric data tests (second). The ANN based on the solar energy supply data tests (third) shows that the distillate prediction is accurate in the range between $5 \mathrm{~L} / \mathrm{h}$ and $10 \mathrm{~L} / \mathrm{h}$ but it fails at higher productions (about $15 \mathrm{~L} / \mathrm{h}$ ). This problem is solved (without over fitting) when all data, that is, coming from electric and solar data tests, are included in the definite ANN model (fourth).

\subsubsection{Activation Function in the Hidden Layer}

The back-propagation algorithm applied requires that the activation function has to be continuous and therefore derivable to obtain the error in the hidden and output neurons [47]. Here, three basic functions that comply with this condition are analyzed in the hidden layer: linear function and sigmoidal functions (log-sigmoid and Tanh). Figure 10 shows a comparison of the MSE and R performance with three different activation functions.

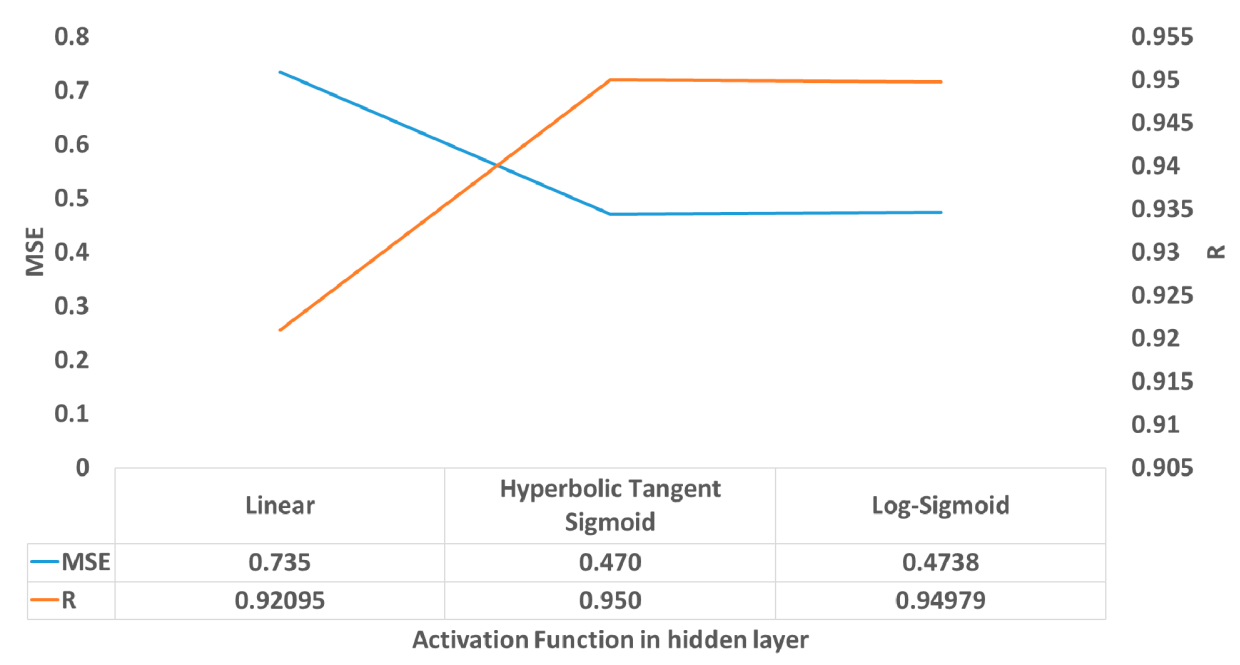

Figure 10. Effect of Activation function on MSE.

Linear activation function proved to have an MSE 56\% higher than Tanh or log-sigmoid cases. On the other hand, a higher $\mathrm{R}$ value was found in the Tanh model, being $0.02 \%$ and $3 \%$ higher than log-sigmoid and linear models, respectively. Regarding the MSE difference between Tanh and log-sigmoid models, it is only about $0.8 \%$, but both functions showed a rather similar behavior. Thus, the ANN model with Tanh as activation function is presented in next sections. Regardless, the ANN model with log-sigmoid activation function will be also presented as supplementary information.

\subsection{ANN Fitting Model to Compute PGMD Production}

Based on the results discussed in Sections 3.1.1-3.1.3, the model presented here is an ANN with structure 3:10:1 trained with electric and solar data sets and Tanh as activation function in the hidden layer.

Equations below include in detail the ANN model parameters for a PGMD. It can be freely used for anyone who wants to estimate the production of this kind of MD. The model can be used during the design stages of new projects or to improve the operation and control in existing facilities.

$$
\begin{gathered}
m_{\text {dist }}=\frac{\left(y_{2}+1\right)(21.12-1.8)}{2}+1.8 \\
y_{2}=[-0.10360 .2843-0.53470 .18891 .7040-1.06880 .72250 .2251-0.44040 .1936]\left[y_{1}\right]-0.095
\end{gathered}
$$




$$
y_{1}=\tanh \left(\left[\begin{array}{c}
2.6307-3.58083 .2941 \\
0.86482 .66912 .9481 \\
2.28130 .6201-1.0012 \\
1.14972 .29423 .9933 \\
1.49421 .6630-1.4243 \\
1.40432 .0807-1.7711 \\
-2.53961 .93541 .2389 \\
-6.24040 .3534-3.3152 \\
-2.30202 .91981 .1061 \\
2.9581-0.56525 .5083
\end{array}\right]\left[\begin{array}{c}
\frac{2\left(T_{c i}-12\right)}{30.6-12}-1 \\
\frac{2\left(T_{e i}-33.1\right)}{80.6-33.1}-1 \\
\frac{2\left(m_{\text {feed }}-160\right)}{500-160}-1
\end{array}\right]+\left[\begin{array}{c}
-2.8264 \\
-3.7409 \\
-1.7708 \\
-1.4090 \\
-1.3074 \\
-1.2844 \\
-1.1861 \\
-0.3998 \\
-1.8377 \\
3.3836
\end{array}\right]\right)
$$

\subsection{ANN Validation}

The 3-D view (Figure 11) of the experimental and predicted production of the PGMD shows that the definite ANN model obtained is flexible, adaptable and is not over fitted. The detail in Figure 11 shows that the ANN accurately predicts the PGMD distillate independently from the feed flow rate or temperature gap between the condenser and evaporator inlets. Thus, the model can adumbrate the production in the range from $200 \mathrm{~L} / \mathrm{h}$ to $500 \mathrm{~L} / \mathrm{h}$ and with a temperature difference band from $10{ }^{\circ} \mathrm{C}$ to $60^{\circ} \mathrm{C}$ between the inlets of the evaporator and condenser for a feed seawater of $35 \mathrm{~g} / \mathrm{kg}$ of salinity. Note that a few samples are only taken in the range from $10{ }^{\circ} \mathrm{C}$ to $30^{\circ} \mathrm{C}$ and the band of $200 \mathrm{~L} / \mathrm{h}$ since the MD performance was rather low (a very high specific thermal energy consumption was found), and the major number of tests were located in the range of $300 \mathrm{~L} / \mathrm{h}$, which allowed the pilot unit to maintain the inlet temperature drop in the range of $30-50{ }^{\circ} \mathrm{C}$ under any sunny condition during the solar tests.

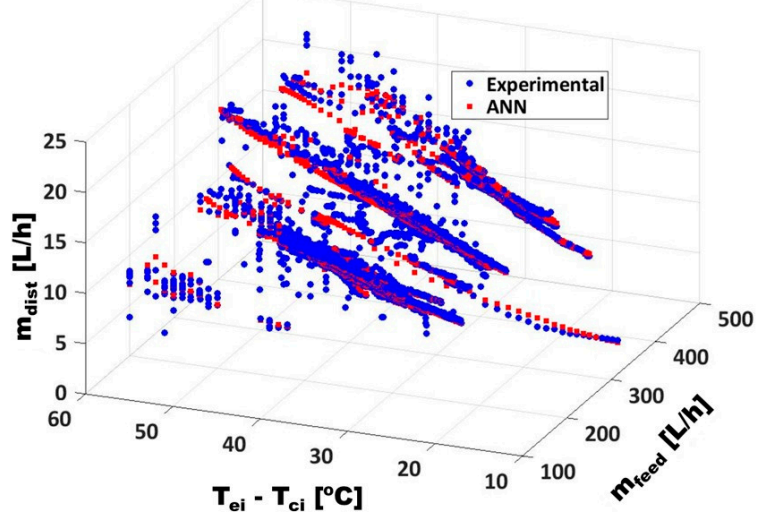

Figure 11. 3D view of compared ANN predictions and experimental values.

To reinforce that this ANN model is not over fitted, results from Winter et al. [13] were also introduced and compared in Figure 12, which shows the same results as those presented in Figure 11, but in a 3-D surface view. The variation of the temperature difference $\left(T_{e i}-T_{c i}\right)$ was constrained from $35{ }^{\circ} \mathrm{C}$ to $55^{\circ} \mathrm{C}$ (with a step of $1{ }^{\circ} \mathrm{C}$ and $20 \mathrm{~L} / \mathrm{h}$ ). Note that in the reference the abovementioned temperature difference was maintained at $55{ }^{\circ} \mathrm{C}\left(80^{\circ} \mathrm{C}\right.$ in evaporator inlet and $25{ }^{\circ} \mathrm{C}$ in condenser inlet) in the tests. Although some deviations were found (green line), the ANN model predicts the PGMD production with rather good accuracy, especially in the range from $200 \mathrm{~L} / \mathrm{h}$ to $400 \mathrm{~L} / \mathrm{h}$ for that energy supply. Furthermore, the ANN model could enlarge the predictions within a wider range of temperature drops and mass flow rates, corresponding to the typical operation of a PGMD only supplied by solar energy. 


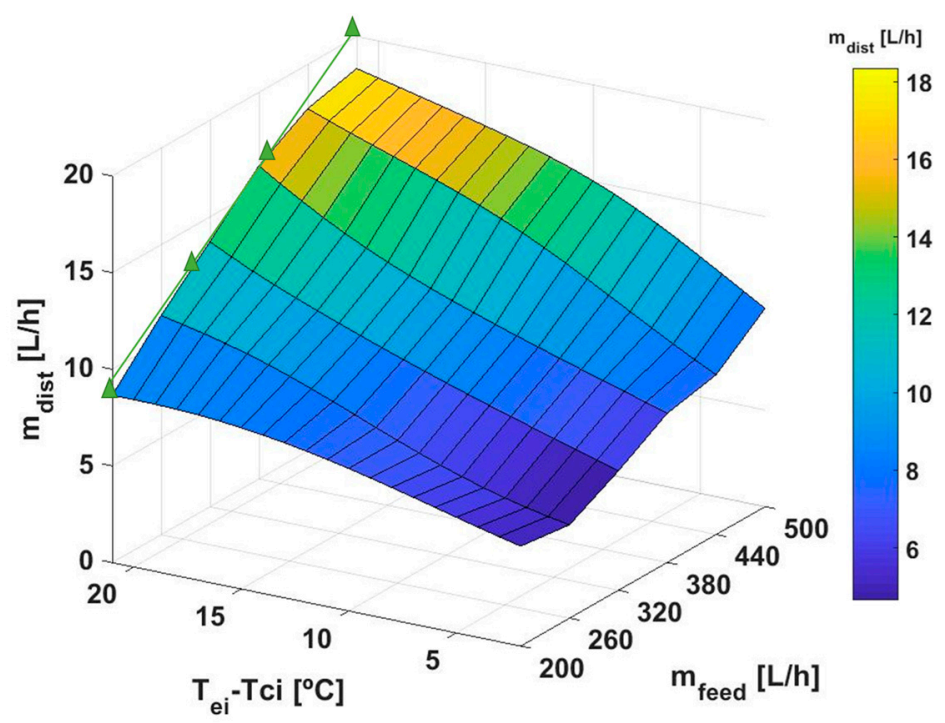

Figure 12. 3-D surface provided by ANN model and comparison with experimental data from the manufacturer [13] (green line).

\subsection{ANN Application}

In order to demonstrate that this ANN model could really improve simulation results, experimental data from 24 July 2017 were used again to compare the linear regression model previously studied, the new predictions from the ANN model, as well as the real production of that day. Figure 13 shows that the linear regression (red line) did not accurately forecast the measured production (blue line). The total fresh water production measured that day was $32.43 \mathrm{~L}$, and the linear regression computed $51.06 \mathrm{~L}$, which implies $58 \%$ error for the total production. On the other hand, it can be seen that the ANN model fits the real data better (grey line): total production computed was $31.42 \mathrm{~L}$, having only a difference of $1.01 \mathrm{~L}$ ( $3 \%$ of error). Major differences were found at the start-up of the PGMD unit, in which the pilot unit is more sensitive than the ANN or regression models to physical phenomena of thermal inertia, being the only time that real values are lower than those predicted by the ANN.

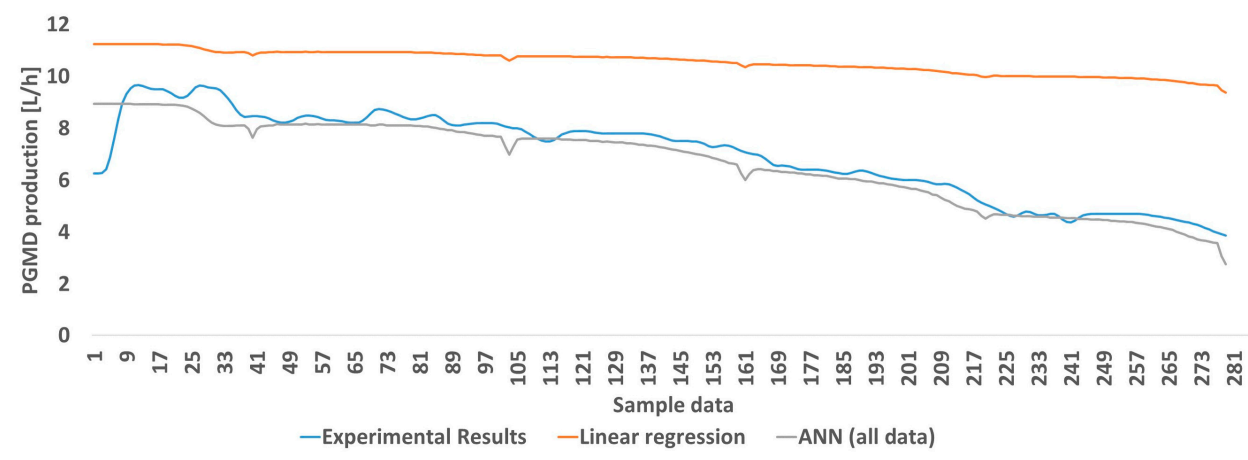

Figure 13. Comparison of distillate predicted by the liner regression model and the one supplied by the ANN model with respect to real data (24 July 2017).

At this point, it is important to remember that the final aim of this paper is to improve the previous simulation model. A new PGMD model has been implemented in the simulation to give a PGMD forecast production, thus substituting the existing model based on the simple linear regression.

Figure 14 shows the PGMD production (grey line) obtained by the PGMD model based on the ANN that uses as input parameters the internal values obtained by the simulation of the complete trigeneration unit. Of course, the new prediction is better than the first estimation based on the linear 
regression type (see Section 2.2), but it does not follow the same accuracy as that of the proper ANN fitting model (Figure 13).

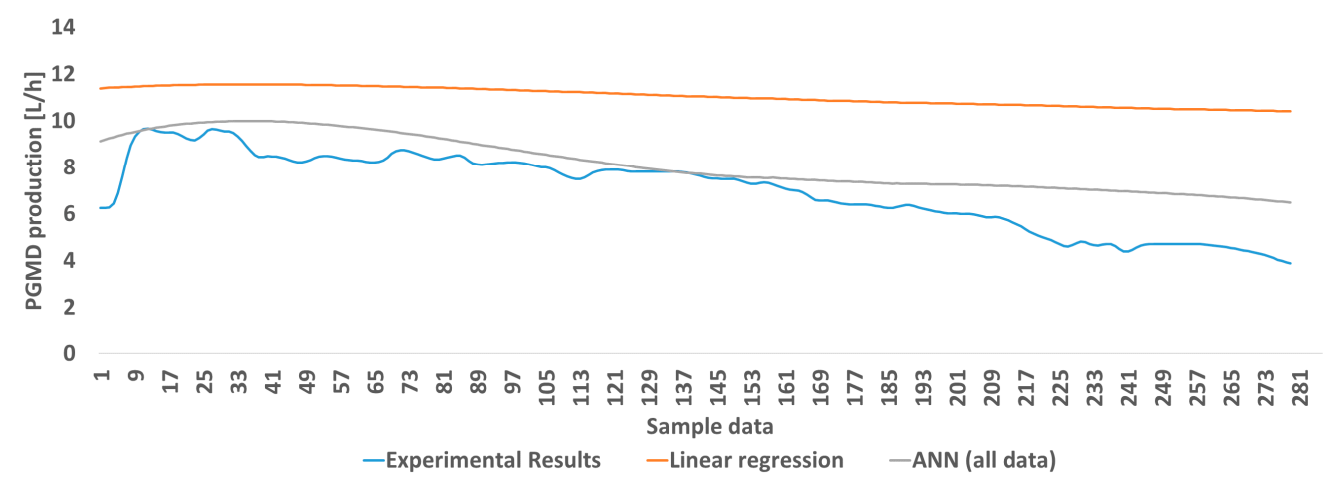

Figure 14. PGMD distillate (grey line) by using the new PGMD-type based on the ANN. The old type is depicted in red (24 July 2017).

At this point, it is important to remember that the simulation presented in [7] involved several subsystems (solar loop, Sanitary Hot Water (SHW) loop, electric package, and fresh water loop). The PGMD could be considered as the last subsystem of the trigeneration unit, thus thermal energy required to its activation hardly depends on the efficiency of solar energy transformation, the SHW demands and the heat transfer effectiveness in the storage tank and the HX Tank-MD. Nevertheless, the new type based on the ANN clearly improved the simulation results by estimating the production as $37.93 \mathrm{~L}$ for that day, which is a $17 \%$ error from the real measured data. Since the ANN model only presented a $3 \%$ error, it can be assumed that $14 \%$ error comes from simulator estimations (use of meteorological databases, assuming constant efficiency parameters in devices, time step approximation errors, etc.).

This means that by combining the use of the ANN model with a dynamic simulator, an improvement of $41 \%$ in the PGMD production could be obtained, that is, error in the PGMD prediction is reduced by more than $70 \%$ in the complete trigeneration scheme.

\section{Discussion}

The ANN model based in three measured parameters of the PGMD unit has been validated with data from the experimental facility as presented in Figure 9 (fourth graphic) and Figure 11. Another validation to demonstrate the wide inlet ranges to apply the ANN is presented in Figure 12, in which some partial comparison with results from [13] can also be seen. When compared with experimental data, the ANN model has proved to predict accurate results of the distillate produced: $3 \%$ was the average error found. For instance, only an underestimation of 1.01 liters per day has been found for a typical day test in the summer period (24 July 2017). This model has also been included in a simulation tool where the results have been improved if compared with the first attempt, i.e., a PGMD type based on the linear regression model extracted from the manufacturer [48]. This is a considerable improvement since the original linear regression model overestimated the production by more than 19 L that day. This means that simulations combined with ANN clearly increased the accuracy of the PGMD production by the software. The error of the simulation with respect to the PGMD production was decreased from $58 \%$ to $17 \%$; thus, PGMD prediction in the simulator was reduced by up to $41 \%$ on the selected day for the analysis.

\section{Conclusions}

In this work, distillate provided by a PGMD was reproduced by means of an artificial neural network (ANN). As a black-box model, the ANN tried to improve the predictions first made by a 
linear regression model, which clearly were overestimated when compared with experimental data taken from the field tests. The ANN model is based on three inlet measured parameters of the PGMD unit, and it has been validated with data from the experimental facility. In the case of the electric tests, the PGMD worked alone under steady experimental conditions. In the case of solar tests, the complete trigeneration unit was operating by consuming solar and wind energy. It is obvious that experimental conditions hardly depend on weather conditions, but thermal energy was stored in a water tank and provided quasi-static conditions to the PGMD unit operation. Those different experimental datasets allowed us to consecutively improve the ANN model performance. Results from the ANN model presented were compared to experimental data of the real trigeneration facility. The performance of the ANN based on all data, that is, using both electric and solar data sets, was substantially better than conventional linear regression. Furthermore, since this ANN model does not depend on the heat supply conditions, that is, it does not use any parameter regarding the heat source (for instance, the flow rate or the temperature drop on the hot side of the HX feeding the PGMD), it can be used for predicting the production behavior for a wide range of operational conditions and energy resources.

To conclude, it is important to remark that its exportable matrix model makes the ANN an excellent option for accurate modelling and real-time optimization in complex systems. Here, the usefulness of the ANN was materialized by improving the complete simulation of a trigeneration scheme based on the unique supply of RES. In this manner, if the adequate prediction of PGMD is available, its fair contribution with respect to the RO production to cover the water demands in this scheme could be found. In this way, the scale-up of this trigeneration scheme with the simulator could be finely used in the search of sustainable management of the decentralized supply of water, electricity and SHW for larger communities in remote and water-scarce areas.

Supplementary Materials: The following are available online at www.mdpi.com/2073-4441/10/3/310/s1, Equations.

Acknowledgments: The authors wish to thank the financial support provided by the Spanish Ministry of Economics and Competiveness in the framework of the "Retos de la Sociedad" R + D Program, under the TRHIBERDE R + D project (ENE2014-59947-R).

Author Contributions: Luis Acevedo conceived and developed the ANN models, and wrote the paper. Javier Uche performed the MD experiments and reviewed the paper. Alejandro Del-Amo developed the simulation model.

Conflicts of Interest: The authors declare no conflict of interest. 


\section{Nomenclature}

$\begin{array}{ll}\text { Acronyms } & \\ \text { AGMD } & \text { Air Gap Membrane Distillation } \\ \text { ANN } & \text { Artificial Neural Network } \\ \text { DCMD } & \text { Direct Contact Membrane Distillation } \\ \text { ETC } & \text { Evacuated Tubes Collector } \\ \text { MED } & \text { Multi-Effect Distillation } \\ \text { MD } & \text { Membrane Distillation } \\ \text { MSE } & \text { Mean Square Error } \\ \text { MSF } & \text { Multi Stage Flash distillation } \\ \text { PGMD } & \text { Permeate Gap Membrane Distillation } \\ \text { PVT } & \text { Photovoltaic Thermal Collector } \\ \text { RES } & \text { Renewable Energy Systems } \\ \text { RO } & \text { Reverse Osmosis } \\ \text { RSM } & \text { Response Surface Methodology } \\ \text { SGMD } & \text { Sweep Gas Membrane Distillation } \\ \text { SHW } & \text { Sanitary Hot Water } \\ \text { SSR } & \text { Residual sum of squares } \\ \text { SST } & \text { Total sum of squares } \\ \text { TDS } & \text { Total Dissolved Solids } \\ \text { VMD } & \text { Vacuum Membrane Distillation } \\ \text { Symbols } & \\ \mathrm{n} & \text { Neurons in hidden layer } \\ \text { N } & \text { Neurons in input layer } \\ \text { R } & \text { Coefficient of determination } \\ \text { T } & \text { Temperature } \\ \text { x } & \text { Input } \\ \text { y } & \text { Output function, predicted value } \\ \text { w } & \text { Weight } \\ \text { Subscripts } & \\ \text { ci } & \text { Eondenser inlet } \\ \text { ei } & \text { Input } \\ \text { I } & \text { Biass } \\ & \end{array}$

\section{References}

1. Khalifa, A.E.; Alawad, S.M.; Antar, M.A. Parallel and series multistage air gap membrane distillation. Desalination 2017, 417, 69-76. [CrossRef]

2. Đurin, B.; Margeta, J. Analysis of the possible use of solar photovoltaic energy in urban water supply systems. Water 2014, 6, 1546-1561. [CrossRef]

3. Gao, L.; Yoshikawa, S.; Iseri, Y.; Fujimori, S.; Kanae, S. An economic assessment of the global potential for seawater desalination to 2050. Water 2017, 9, 763. [CrossRef]

4. González, D.; Amigo, J.; Suárez, F. Membrane distillation: Perspectives for sustainable and improved desalination. Renew. Sustain. Energy Rev. 2017, 80, 238-259. [CrossRef]

5. Caldera, U.; Bogdanov, D.; Afanasyeva, S.; Breyer, C. Role of seawater desalination in the management of an integrated water and 100\% renewable energy based power sector in Saudi Arabia. Water 2018, 10, 3. [CrossRef]

6. Janajreh, I.; El Kadi, K.; Hashaikeh, R.; Ahmed, R. Numerical investigation of air gap membrane distillation (AGMD): Seeking optimal performance. Desalination 2017, 424, 122-130. [CrossRef]

7. Acevedo, L.; Uche, J.; Del Amo, A.; Cirez, F.; Usón, S.; Martínez, A.; Guedea, I. Dynamic simulation of a trigeneration scheme for domestic purposes Based on hybrid techniques. Energies 2016, 9, 1013. [CrossRef]

8. Camacho, L.; Dumée, L.; Zhang, J.; Li, J.; Duke, M.; Gomez, J.; Gray, S. Advances in membrane distillation for water desalination and purification applications. Water 2013, 5, 94-196. [CrossRef] 
9. Eykens, L.; Reyns, T.; De Sitter, K.; Dotremont, C.; Pinoy, L.; Van der Bruggen, B. How to select a membrane distillation configuration? Process conditions and membrane influence unraveled. Desalination 2016, 399, 105-115. [CrossRef]

10. Alklaibi, A.M.; Lior, N. Transport analysis of air-gap membrane distillation. J. Membr. Sci. 2005, 255, $239-253$. [CrossRef]

11. Khayet, M. Membranes and theoretical modeling of membrane distillation: A review. Adv. Colloid Interface Sci. 2001, 164, 56-88. [CrossRef] [PubMed]

12. Ugrozov, V.V.; Elkina, I.B.; Nikulin, V.N.; Kataeva, L.I. Theoretical and experimental research of liquid-gap membrane distillation process in membrane module. Desalination 2003, 157, 325-331. [CrossRef]

13. Winter, D.; Koschikowsky, J.; Wieghaus, M. Desalination using membrane distillation: Experimental studies on full scale spiral wound modules. J. Membr. Sci. 2011, 375, 104-112. [CrossRef]

14. Khayet, M.; Matsuura, T. Membrane Distillation Principles and Applications; Elsevier: Amsterdam, The Netherlands, 2011; pp. 249-293. ISBN 978-0-4445-3126-1.

15. Cao, W.; Liu, Q.; Wang, Y.; Mujtaba, I.M. Modeling and simulation of VMD desalination process by ANN. Comput. Chem. Eng. 2016, 84, 96-103. [CrossRef]

16. Alpaydin, E. Introduction to Machine Learning, 2nd ed.; MIT Press: Cambridge, MA, USA, 2009; pp. $233-275$. ISBN 978-0-262-01243-0.

17. Samarasinghe, S. Neural Networks for Applied Sciences and Engineering; Auerbach Publications: New York, NY, USA, 2006; pp. 11-67. ISBN 978-0-8493-3375-0.

18. Mackay, D. Information Theory, Inference, and Learning Algorithms; Cambridge University Press: Cambridge, UK, 2005; pp. 233-258. ISBN 978-0-5216-4298-9.

19. Kalogirou, S.A. Applications of artificial neural-networks for energy systems. Appl. Energy 2000, 67, 17-35. [CrossRef]

20. Pasini, A.; Langone, R. Attribution to precipitation changes on a regional scale by network modeling: A case study. Water 2010, 2, 321-332. [CrossRef]

21. Kim, S.; Singh, V. Spatial disaggregation of areal rainfall using two different artificial neural networks models. Water 2015, 7, 2707-2727. [CrossRef]

22. Jiao, G.; Guo, T.; Ding, Y. A new hybrid forecasting approach applied to hydrological data: A case study on precipitation in Northwestern China. Water 2016, 8, 367. [CrossRef]

23. Bogner, K.; Liechti, K.; Zappa, M. Post-processing of stream flows in Switzerland with an emphasis on low flows and floods. Water 2016, 8, 115. [CrossRef]

24. Wang, J.; Shi, P.; Jiang, P.; Hu, J.; Qu, S.; Chen, X.; Chen, Y.; Dai, Y.; Xiao, Z. Application of BP neural network algorithm in traditional hydrological model for flood forecasting. Water 2017, 9, 48. [CrossRef]

25. Jimeno-Sáez, P.; Senent-Aparicio, J.; Pérez-Sánchez, J.; Pulido-Velazquez, D.; Cecilia, J. Estimation of instantaneous peak flow using machine-learning models and empirical formula in peninsular Spain. Water 2017, 9, 347. [CrossRef]

26. Taravat, A.; Rajaei, M.; Emadodin, I.; Hasheminejad, H.; Mousavian, R.; Biniyaz, E. A spaceborne multisensory, multitemporal approach to monitor water level and storage variations of lakes. Water 2016, 8, 478. [CrossRef]

27. Zhou, T.; Wang, F.; Yang, Z. Comparative analysis of ANN and SVM models combined with wavelet preprocess for groundwater depth prediction. Water 2017, 9, 781. [CrossRef]

28. Jang, D.; Choi, G. Estimation of non-revenue water ratio using MRA and ANN in water distribution networks. Water 2018, 10, 2. [CrossRef]

29. Gao, P.; Zhang, L.; Cheng, K.; Zhang, H. A new approach to performance analysis of a seawater desalination system by an artificial neural network. Desalination 2007, 205, 147-155. [CrossRef]

30. Aish, A.M.; Zaqoot, H.A.; Abdeljawad, S.M. Artificial neural network approach for predicting reverse osmosis desalination plants performance in the Gaza Strip. Desalination 2015, 367, 240-247. [CrossRef]

31. Cabrera, P.; Carta, J.A.; González, J.; Melián, G. Artificial neural networks applied to manage the variable operation of a simple seawater reverse osmosis plant. Desalination 2017, 416, 140-156. [CrossRef]

32. Cabrera, P.; Carta, J.A.; González, J.; Melián, G. Wind-driven SWRO desalination prototype with and without batteries: A performance simulation using machine learning models. Desalination 2017. [CrossRef]

33. Barello, M.; Manca, D.; Patel, R.; Mujtaba, I.M. Neural network based correlation for estimating water permeability constant in RO desalination process under fouling. Desalination 2014, 345, 101-111. [CrossRef] 
34. Khayet, M.; Cojocaru, C.; Essalhi, M. Artificial neural network modeling and response surface methodology of desalination by reverse osmosis. J. Membr. Sci. 2011, 368, 202-214. [CrossRef]

35. Khayet, M.; Cojocaru, C. Artificial neural network modeling and optimization of desalination by air gap membrane distillation. Sep. Purif. Technol. 2012, 86, 171-182. [CrossRef]

36. Khayet, M.; Cojocaru, C. Artificial neural network model for desalination by sweeping gas membrane distillation. Desalination 2013, 308, 102-110. [CrossRef]

37. Magnier, L.; Haghighat, F. Multi-objective optimization of building design using TRNSYS simulations, genetic algorithm, and artificial neural network. Build. Environ. 2010, 45, 739-746. [CrossRef]

38. Asadi, E.; Gameiro da Silva, M.; Antunes, C.H.; Dias, L.; Glicksman, L. Multi-objective optimization for building retrofit: A model using genetic algorithm and artificial neural network and an application. Energy Build. 2014, 81, 444-456. [CrossRef]

39. Buratti, C.; Orestano, F.C.; Palladino, D. Comparison of the energy performance of existing buildings by means of dynamic simulations and artificial neural networks. Energy Procedia 2016, 101, 176-183. [CrossRef]

40. Souliotis, M.; Kalogirou, S.; Tripanagnostopoulos, Y. Modelling of an ICS solar water heater using artificial neural networks and TRNSYS. Renew. Energy 2009, 34, 1333-1339. [CrossRef]

41. Afram, A.; Janabi-Sharifi, F.; Fung, A.; Raahemifar, K. Artificial neural network (ANN) based model predictive control (MPC) and optimization of HVAC systems: A state of the art review and case study of a residential HVAC system. Energy Build. 2017, 141, 96-113. [CrossRef]

42. Bayod, A.; Martínez, A.; Acevedo, L.; Uche, J.; Usón, S. Improved management of battery and fresh water production in grid connected PVT systems in dwellings. In 10th BIWAES Biennial International Workshop Advances in Energy Studies, Naples, Italy, 25-28 September 2017; Ulgiati, S., Vanoli, L., Eds.; Graz University of Technology: Graz, Austria, 2017.

43. Acevedo, L.; Uche, J.; Usón, S.; Cirez, F.; Martínez, A.; Bayod, A.; Jiang, G. Exergy analysis of the transient simulation of a renewable-based trigeneration scheme for domestic water and energy supply. In 10th BIWAES Biennial International Workshop Advances in Energy Studies, Naples, Italy, 25-28 September 2017; Ulgiati, S., Vanoli, L., Eds.; Graz University of Technology: Graz, Austria, 2017.

44. Acevedo, L.; Uche, J.; Usón, S.; Jiang, G.; Del Amo, A.; Martínez, A.; Bayod, A. Modelling and simulating a trigeneration plant: Coupling exergy analysis and Trnsys simulation by the creation of new types. In Proceedings of the International Conference on Energy, Environment and Economics, Edinburgh, Scotland, 11-13 December 2017.

45. Acevedo, L.; Uche, J.; Cirez, F.; Usón, S.; Martínez, A.; Bayod, A. Experimental analysis of a domestic trigeneration scheme feed by photovoltaic/thermal (PVT) collectors. In 10th BIWAES Biennial International Workshop Advances in Energy Studies, Naples, Italy, 25-28 September 2017; Ulgiati, S., Vanoli, L., Eds.; Graz University of Technology: Graz, Austria, 2017.

46. Beale, M.H.; Hagan, M.T.; Demuth, H.B. Neural Network Toolbox Design Book; MathWorks Inc.: Natick, MA, USA, 2017.

47. Quintín, M.; Sanatana, Y. Application of Artificial Neural Networks to Regression; La Muralla: Madrid, Spain, 2007; pp. 78-99. ISBN 978-84-7133-767-2.

48. Winter, D.; Koschikowsky, J.; Ripperger, S. Desalination using membrane distillation: Flux enhancement by feed water deaeration on spiral-wound modules. J. Membr. Sci. 2012, 423-424, 215-224. [CrossRef]

(C) 2018 by the authors. Licensee MDPI, Basel, Switzerland. This article is an open access article distributed under the terms and conditions of the Creative Commons Attribution (CC BY) license (http:/ / creativecommons.org/licenses/by/4.0/). 